\title{
Cardiovascular risk in an HIV-infected population in India
}

\author{
Ivan P Marbaniang, ${ }^{1}$ Dileep Kadam, ${ }^{2}$ Rohan Suman, ${ }^{2}$ Nikhil Gupte, ${ }^{1,3}$ Sonali Salvi, ${ }^{2}$ \\ Sandesh Patil, ${ }^{1}$ Dhananjay Shere, ${ }^{1}$ Prasad Deshpande, ${ }^{1}$ Vandana Kulkarni, ${ }^{1}$ \\ Andrea Deluca, ${ }^{1,4}$ Amita Gupta, ${ }^{1,3}$ Vidya Mave ${ }^{1,3}$
}

\begin{abstract}
- Additional material is published online only. To view please visit the journal online (http://dx.doi.org/10.1136/ heartasia-2017-010893).

${ }^{1}$ Byramjee Jeejeebhoy Government Medical College - Johns Hopkins University Clinical Research Site, Pune, Maharashtra, India ${ }^{2}$ Department of Medicine, Byramjee Jeejeebhoy Government Medical College, Pune, Maharashtra, India ${ }^{3}$ Johns Hopkins University School of Medicine, Baltimore, Maryland, USA

${ }^{4} J o h n s$ Hopkins University Bloomberg School of Public Health, Baltimore, Maryland, USA
\end{abstract}

\section{Correspondence to} Dr Ivan P Marbaniang, 1st Floor, Pathology Museum, 12 BJ Medical College Clinical Trials Unit, Jai Prakash Narayan Road, Pune, Maharashtra; ivanmarb@ gmail.com

Received 14 February 2017 Revised 2 June 2017 Accepted 3 June 2017

\section{ABSTRACT \\ Objective To characterise prevalence of traditional cardiovascular disease (CVD) risk factors, assess CVD risk and examine the effect of simulated interventions on CVD risk among HIV-infected Asian Indians.}

Methods Cross-sectional data between September 2015 and July 2016 wer used to describe the prevalence of CVD risk factors. Five risk scores (Framingham, Data Collection on Adverse Effects of Anti-HIV Drugs Study (D:A:D), Atherosclerotic Cardiovascular, QRISK2 and Ramathibodi-Electricity Generating Authority of Thailand were used to estimate CVD risk. The effect of seven sensitivity analyses: smoking prevention; diabetes prevention; optimal blood pressure and dyslipidaemia control (total cholesterol, high-density lipoprotein (HDL)); CD4 augmentation and a combination of the scenarios on the median cumulative $D: A: D$ CVD scores were assessed.

Results Of 402 enrolled, 56\% were women, median age was 40 years (IQR: $35-45$ years) and median time-updated CD4 counts were 378 cells/ $\mu \mathrm{L}$ (IQR: 246-622). Fifty-five and 28\% had ever been screened for hypertension and diabetes, respectively prior to enrolment. The prevalence of diabetes, hypertension, hypercholesterolaemia, low HDL, previous and current smokers were 9\%,22\%, 20\%,39\%, 14\% and $4 \%$, respectively. Thirty-six per cent had intermediate-tohigh 5-year CVD risk by D:A:D estimates. Thirty-two per cent were eligible for statin therapy by American College of Cardiology/American Heart Association guidelines; 2\% were currently on statins. In sensitivity analyses, diabetes prevention was associated with the highest reduction of CVD risk.

Conclusion CVD at younger ages among Asian Indian people living with HIV appear to be an imminent risk for morbidity. Stepping up of preventive services including screening services and prescription of statins are important strategies that must be considered.

\section{INTRODUCTION}

An estimated 2.1 million people in India have HIV, with adults ( $\geq 15$ years) constituting 93\% of those infected. ${ }^{1}$ Wider access to antiretroviral therapy (ART) under the national programme has led to a decrease in AIDS-related deaths. Between 2007 and 2011, annual AIDS-related deaths have reduced by $27 \%$ and the scale-up of ART services will prevent 50000-60000 deaths in the next 5 years. ${ }^{2}$ Presently, non-AIDS defining conditions including cardiovascular diseases (CVDs), predominate causes of morbidity and mortality among people living with HIV (PLWH) on suppressive combination $\mathrm{ART}^{3-6}$ In the past, this was largely attributed to the use of certain classes of antiretroviral drugs. It is now recognised that HIV-induced immune activation, chronic inflammation ${ }^{78}$ and the higher prevalence of traditional CVD risk factors like diabetes, hypertension and smoking ${ }^{9}{ }^{10}$ among PLWH, all contribute to increased CVD risk. Nonetheless, limited geographically relevant CVD risk factor data impede efforts to plan interventions to mitigate CVD risk in Asian Indian PLWH.

Among the general population of India, there has been a similar epidemiological transition in the causes of death from infectious to non-infectious aetiologies. According to the Global Burden of Disease Study, 29\% of all deaths in India are attributable to $\mathrm{CVD},{ }^{11}$ which also occur at an earlier age. In India, $52 \%$ of these deaths occur before the age of 70 compared with $23 \%$ in those with European ancestry. ${ }^{12}$ This difference has been explained by genetic factors as well as the clustering of traditional risk factors at a younger age. ${ }^{13-15}$ Whether this difference is inflated in those with concomitant $\mathrm{HIV}$ infection has not been well described, and it remains unclear if Asian Indians living with HIV are at an even higher risk of CVD at younger ages than the general population.

Multiple CVD risk scores have been developed to focus behavioural modifications and therapeutic options. The Framingham risk score, the most widely used risk estimator, uses conventional CVD risk factors to appropriate CVD risk. The more recently developed Atherosclerotic Cardiovascular Disease (ASCVD) risk estimator, from the American College of Cardiology/ American Heart Association (ACC/AHA) accounts for White, African American and Other ethnicity in providing statin prescription recommendations. Risk calculators that account specifically for Asian ethnicity include QRISK2Indian ethnicity and Ramathibodi-Electricity Generating Authority of Thailand (RAMA-EGAT), which was developed using a Southeast Asian cohort. The only risk estimator designed for PLWH comes from the Data Collection on Adverse Events of Anti-HIV Drugs (D:A:D) study and incorporates traditional CVD risk factors with HIV infection and treatment characteristics (table 1). None of these risk scores however, take into account, the cumulative effect of an Asian Indian ethnicity and HIV-related factors while predicting CVD risk. It is therefore conceivable that these commonly used risk calculators would underestimate the burden that CVD pose for Asian Indians PLWH. 


\begin{tabular}{ll}
\hline Table 1 & D:A:D cardiovascular disease 5 -year risk score \\
\hline Factor & Unit \\
\hline Age & Years \\
\hline Sex & Male/female \\
\hline Previous smoker & Yes/no \\
\hline Current smoker & Yes/no \\
\hline Family CVD history & Yes/no \\
\hline Diabetes & Yes/no \\
\hline Abacavir treatment & Yes/no \\
\hline Protease inhibitor exposure & Years \\
\hline NRTI exposure & Years \\
\hline Time-updated CD4 cell count & Cells/ $\mu \mathrm{L}$ \\
\hline Systolic blood pressure & $\mathrm{mm} \mathrm{Hg}$ \\
\hline Total cholesterol & $\mathrm{mmol} / \mathrm{L}$ \\
\hline HDL & $\mathrm{mmol} / \mathrm{L}$ \\
\hline
\end{tabular}

Estimation of the predicted 5-year risk is done using Cox models.

The full D:A:D model includes all the covariates listed above and is used when cumulative NRTI exposure is up to 10 years and PI exposure is up to 6 years. For

individuals who are highly exposed to either NRTIs or PIs, a simpler D:A:D model is used to prevent overestimation of CVD risk. The simpler model excludes the covariates for abacavir treatment, $\mathrm{PI}$ and NRTI exposure times.

A more detailed explanation of the $D: A: D$ equation is given in the online supplementary appendix 1.

CVD, cardiovascular disease; D:A:D, Data Collection on Adverse Events of Anti-HIV Drugs; HDL, high-density lipoprotein; NRTI, nucleoside reverse-transcriptase inhibitor; PI, protease inhibitor.

We therefore sought to assess the prevalence of CVD risk factors and explore CVD risk scores using the five risk estimators described. We further attempted to assess the effect of different hypothetical scenarios, namely smoking prevention, diabetes prevention, prescription of total cholesterol, high-density lipoprotein cholesterol (HDL-c), blood pressure to recommended National Heart, Lung and Blood Institute (NHLBI) guidelines and CD4 counts to the Strategic Timing of Antiretroviral Treatment (START) $\operatorname{study}^{16}$ recommendations on the $\mathrm{D}: \mathrm{A}: \mathrm{D}$ risk score.

\section{METHODS}

\section{Study design and population}

Participants were enrolled from the ART Centre of Byramjee Jeejeebhoy Government Medical College and Sassoon General Hospitals (BJGMC), a large urban public teaching hospital in Maharashtra, India. The ART Centre at BJGMC is supported by the National AIDS Control Organization (NACO) and caters to about $35000 \mathrm{HIV}$-infected individuals from the surrounding urban, semiurban and rural areas.

HIV-positive individuals were eligible for study proceedings if they fulfilled the following criteria: (1) were $\geq 18$ years of age; (2) had been on ART for $\geq 1$ year (referred to as ART experienced) or had been on ART $\leq 7$ days (referred to as ART naive) and (3) were willing to provide a written informed consent.

Enrolment into the study began on 1 September 2015, and we included all data collected until 12 July 2016.

\section{Study assessments}

Two dedicated study counsellors approached participants attending the ART centre of BJGMC and obtained a convenience sample of those who were interested to take part in study procedures. Demographic, social, clinical including treatment history were elicited from the participants. CD4 counts are routinely done every 6 months under the national programme and we abstracted the first, nadir and time-updated CD4 counts as well as any change in drug regimens from the participant treatment records. Standard procedures were followed for anthropometric measurements of weight, height and waist circumference. Three blood pressure recordings were taken in the sitting position. All data were captured on electronic data capture devices using an online and offline data capture system developed by Persistent Systems, which were then relayed to a secure remote cloudbased server, from where they were downloaded for analyses.

Participants provided fasting blood samples for blood glucose, haemoglobin A1c (HbA1c) and a lipid profile (total cholesterol, triglycerides, HDL, low-density lipoprotein (LDL)). Blood was also collected for HIV viral RNA determination. BJGMC Ethics committee and Johns Hopkins University Institutional Review Board approved this project.

\section{Study definitions}

We determined 10-year cardiovascular risk scores using Framingham with lipids, 2013 ASCVD (for those between 40 and 79 years), QRISK2 and RAMA-EGAT risk estimators. The D:A:D risk equation provided 5-year CVD risks (details of the equation are given in the online supplementary appendix 1). Participants were further delineated into low risk (D:A:D score: $<1 \%$, ASCVD score: $<5 \%$ ), intermediate risk (D:A:D score: $1 \%-5 \%$, ASCVD score: $5 \%-7.5 \%$ ) and high risk (D:A:D score $>5 \%$, ASCVD score $\geq 7.5 \%$ ) according to published literature. Lifetime risk scores were determined using the 30-year Framingham with lipids, 2013 ASCVD (for those between 20 and 59 years) and QRISK lifetime score calculator. ${ }^{17}$ Scores were derived only for those without a prior history of CVD. Cumulative CVD risk was calculated by adding the individually derived CVD risk scores of all participants. Risk scores for normal populations used for the calculation of 10-year cumulative risk differences were obtained from the official QRISK2 and Framingham websites. ${ }^{18} 19$ We determined the proportion of people eligible for statin use based on the ACC/AHA and National Institute for Health and Care Excellence (NICE) guidelines. ${ }^{20} 21$

Participants were classified as being diabetic either if they had been diagnosed with diabetes in the past or as per American Diabetes Association guidelines (fasting blood sugar $\geq 7 \mathrm{mmol} / \mathrm{L}$ or HbA1c $\geq 6.5 \%$ ). Similarly, participants were classified as being hypertensive according to AHA guidelines (systolic blood pressure $\geq 140 \mathrm{~mm} \mathrm{Hg}$, diastolic blood pressure $\geq 90 \mathrm{~mm} \mathrm{Hg}$ or on antihypertensive medication). Dyslipidaemia was defined according to the US National Cholesterol Education Program (NCEP) III guidelines. These include total cholesterol $\geq 5.2 \mathrm{mmol} / \mathrm{L}$, LDL cholesterol $\geq 3.4 \mathrm{mmol} / \mathrm{L}$, triglycerides $\geq 1.7 \mathrm{mmol} / \mathrm{L}, \quad \mathrm{HDL} \leq 1 \mathrm{mmol} / \mathrm{L}$. Metabolic syndrome was defined using both the NCEP III and International Diabetes Federation guidelines.

\section{Statistical analyses}

We described the prevalence of cardiovascular risk factors using medians and proportions. Interscore agreement was defined using a kappa statistic. The impact of different hypothetical scenarios on the median cumulative D:A:D risk score was evaluated. The scenarios included: (1) all smokers (former and current smokers) became non-smokers; (2) all with diabetes became without diabetes; (3) all those with high cholesterol reduced to $5.2 \mathrm{mmol} / \mathrm{L}$; (4) all those with low HDL-c increased to $1 \mathrm{mmol} / \mathrm{L}$; (5) all those with high systolic blood pressure capped to a mean systolic blood pressure of $130 \mathrm{~mm} \mathrm{Hg}$; (6) all those with low time-updated CD4 counts increased to 500 cells/ $\mu \mathrm{L}$ and (7) combination of scenarios 1-6.

Recommendations from the NHLBI were used to define target levels for total cholesterol, HDL and systolic blood pressure and 
a guiding CD4 value of 500 cells $/ \mu \mathrm{L}$ for scenario six was used keeping the findings of the START study in mind. Analyses was performed using STATA V.13.1 and graphs were created using GraphPad PRISM V.7 (GraphPad Software, La Jolla, California, USA).

\section{RESULTS}

\section{Risk factor profile and HIV-related characteristics}

A total of 402 participants were enrolled between 1 September 2015 and 12 July 2016. Blood samples were obtained for 390 (97\%) participants. Median age was 40 years (IQR: 35-45 years), $224(56 \%)$ were women and $290(72 \%)$ had received at least a high school education. Overweight Body Mass Index (BMI) $\geq 25 \mathrm{~kg} / \mathrm{m}^{2}$ and $<30 \mathrm{~kg} / \mathrm{m}^{2}$ ) and obese participants (BMI $\geq 30 \mathrm{~kg} / \mathrm{m}^{2}$ ) constituted $15 \%$ and $1 \%$ of the study population, respectively. Fifty-six participants (14\%) reported to have ever smoked, of which 16 (28\%) were current smokers, all of them being men. Hypercholesterolaemia, hypertriglyceridaemia, high LDL and low HDL were present among 20\%, 25\%, 17\% and $39 \%$ of the enrollees, respectively. Fifty-five per cent had ever been screened for hypertension and $28 \%$ for diabetes prior to enrolment in the study. The overall prevalence of hypertension was $22 \%$ and that of diabetes $9 \%$, with $13 \%$ and $3 \%$ receiving a new diagnosis of hypertension and diabetes, respectively, as a result of the study's screening. A sedentary lifestyle appeared to be low; $73 \%$ of the participants were involved in physical activity consistent with WHO recommendations. However, almost no study participant's dietary habits were in compliance with WHO guidelines (table 2).

A majority $(323,80 \%)$ were on ART at enrolment, of which 65 (20\%) were receiving protease inhibitors (PI) either in the form of boosted atazanavir or boosted lopinavir-based therapy. The median duration of ART exposure was 6.1 years (IQR: 2.9-8.5) for the ART experienced group. Median CD4 cell count was 378 cells/ $\mu$ L (IQR: 246-622) and 191 (49\%) had undetectable viral loads (59\% of ART experienced and 7\% of ART-naive).

\section{Risk scores estimates}

Comparison of short-term CVD risk profiles (5 years for D:A:D score and 10 years for the rest) showed that a majority of the participants were classified as low risk or $<10 \% \mathrm{CVD}$ risk (table 3). However across all scores, we observed that at least $10 \%$ of the participants have either an intermediate/high risk or $\geq 10 \%$ short-term risk for CVD. Using the D:A:D scores exclusively, $36 \%$ of the participants were classified as having an intermediate to high risk of having a CVD event over the next 5 years. Long-term comparison of lifetime risk scores also yielded similar results, with most participants having $<50 \%$ risk of CVD, although these proportions varied widely across scores. Thirty-two per cent were eligible for statins under ASCVD guidelines but only $2 \%$ were on them. Of those enrolled, $7(2 \%)$ had manifest CVD and these individuals were excluded from CVD risk estimation.

\section{Actual and hypothetical median cumulative D:A:D score estimates}

From actual data, the median cumulative D:A:D score was 2.19 , implying that cumulatively for $50 \%$ of our study cohort CVD risk over the next 5 years is $2.19 \%$. (table 4). Similarly, using hypothetical scenarios described earlier, corresponding median cumulative D:A:D scores were: (1) 1.90 when all smokers (former and current) were assumed to be non-smokers; (2) 1.84 when all with diabetes were assumed
Table 2 Study population characteristics

\begin{tabular}{|c|c|c|}
\hline Characteristic & $\mathrm{N}$ & $\%$ \\
\hline Female & $224 / 402$ & 55.7 \\
\hline Age (years) (median (IQR)) & & $40(35-45)$ \\
\hline BMI $\left(\mathrm{kg} / \mathrm{m}^{2}\right)$ (median (IQR)) & & $20.8(18.0-23.6)$ \\
\hline \multicolumn{3}{|l|}{ BMI categories } \\
\hline Underweight $\left(<18.5 \mathrm{~kg} / \mathrm{m}^{2}\right)$ & $118 / 397$ & 29.7 \\
\hline Normal $\left(\geq 18.5\right.$ to $\left.<25 \mathrm{~kg} / \mathrm{m}^{2}\right)$ & $213 / 397$ & 53.6 \\
\hline Overweight ( $\geq 25$ to $<30 \mathrm{~kg} / \mathrm{m}^{2}$ ) & $61 / 397$ & 15.4 \\
\hline Obese $\left(\geq 30 \mathrm{~kg} / \mathrm{m}^{2}\right)$ & $5 / 397$ & 1.3 \\
\hline \multicolumn{3}{|l|}{ Hypercholestrolaemia } \\
\hline (Total cholesterol $\geq 5.2 \mathrm{mmol} / \mathrm{L}$ ) & $79 / 390$ & 20.2 \\
\hline \multicolumn{3}{|l|}{ Low HDL } \\
\hline (HDLs $1 \mathrm{mmol} / \mathrm{L})$ & $152 / 390$ & 38.9 \\
\hline \multicolumn{3}{|l|}{ Hypertriclyceridaemia } \\
\hline (Triglycerides $\geq 1.7 \mathrm{mmol} / \mathrm{L}$ ) & $97 / 390$ & 24.9 \\
\hline \multicolumn{3}{|l|}{ High LDL cholesterol } \\
\hline (LDL cholesterol $\geq 3.4 \mathrm{mmol} / \mathrm{L})$ & $68 / 390$ & 17.4 \\
\hline SBP/DBP (mm Hg) (median (IQR)) & & $\begin{array}{l}115 / 80(105 / 73- \\
127 / 87)\end{array}$ \\
\hline Ever screened for hypertension & $223 / 402$ & 55.5 \\
\hline Hypertension & $90 / 402$ & 22.4 \\
\hline Positive family history of CVD & $43 / 402$ & 10.7 \\
\hline Positive for CVD & $7 / 398$ & 1.8 \\
\hline On statins & $8 / 402$ & 2.0 \\
\hline Ever screened for diabetes & $114 / 402$ & 28.3 \\
\hline Diabetes mellitus & $34 / 390$ & 8.7 \\
\hline Prediabetes & $74 / 390$ & 19.0 \\
\hline \multicolumn{3}{|l|}{ Metabolic syndrome } \\
\hline (IDF definition) & $68 / 385$ & 17.7 \\
\hline (NCEP/ATP III) & $83 / 398$ & 20.8 \\
\hline $\begin{array}{l}\text { WHO recommended daily fruit and vegetable } \\
\text { intake for } 1 \text { week }\end{array}$ & $3 / 402$ & 0.7 \\
\hline WHO recommended physical activity & $290 / 398$ & 73.0 \\
\hline \multicolumn{3}{|l|}{ Smoking } \\
\hline Previous & $56 / 402$ & 14.0 \\
\hline Current & $16 / 402$ & 4.0 \\
\hline CD4 count (cells/ $\mu \mathrm{L}$ ) (median (IQR)) & & $378(246-622)$ \\
\hline CD4 less than 350 cells $/ \mu \mathrm{L}$ & $184 / 398$ & 46 \\
\hline HIV viral load (copies/mL) (median (IQR)) & & $45(<40-1377)$ \\
\hline Undetectable HIV viral load & $191 / 390$ & 49.0 \\
\hline HIV infection duration (years) (median (IQR)) & & $7.1(2.5-10.7)$ \\
\hline On HAART & $323 / 402$ & 80.3 \\
\hline Duration of HAART (years) (median (IQR)) & & $4.5(1.4-8.2)$ \\
\hline Current PI use & $65 / 323$ & 20.1 \\
\hline $\mathrm{ATV} / \mathrm{r}$ & $60 / 65$ & 15.0 \\
\hline $\mathrm{LPV} / \mathrm{r}$ & $5 / 65$ & 7.7 \\
\hline Duration of PI use (years) (median (IQR)) & & $1.8(1.0-3.5)$ \\
\hline
\end{tabular}

Metabolic syndrome: IDF definition: Waist circumference $\geq 90 \mathrm{~cm}$ in male or $\geq 80 \mathrm{~cm}$ in female and any two of the following factors triglycerides $\geq 1.7 \mathrm{mmol} / \mathrm{L} ; \mathrm{HDL}$

$<1 \mathrm{mmol} / \mathrm{Lmg} / \mathrm{dL}$ (male), $<1.3 \mathrm{mmol} / \mathrm{L}$ (female); fasting blood sugar $\geq 5.5 \mathrm{mmol} / \mathrm{L}$ or previously diagnosed diabetes; $S B P \geq 130 \mathrm{~mm} \mathrm{Hg}$ or DBP $\geq 85 \mathrm{~mm}$ or previously diagnosed hypertensive. NCEP-ATPIII definition: any three of the factors used in the IDF definition. WHO recommended fruit and vegetable intake: At least 5 servings of each per day. WHO recommended physical activity: $75 \mathrm{~min}$ of vigorous activity or $150 \mathrm{~min}$ of moderate activity per week.

ATP III, Adult Treatment Panel III; ATV/r, ritonavir-boosted atazanavir; CVD, cardiovascular disease; DBP, diastolic blood pressure; HAART, highly active antiretroviral therapy; HDL, high-density lipoprotein; IDF, International Diabetes Federation; LDL, low-density lipoprotein; LPV/r, ritonavir-boosted lopinavir; NCEP, National Cholesterol Education

Program; PI, protease inhibitor; SBP, systolic blood pressure.

to be without diabetes; (3) 2.03 when cholesterol was set to $5.2 \mathrm{mmol} / \mathrm{L}$ in those with high cholesterol; (4) 2.05 when HDL 


\section{Original research}

Table 3 Comparison between different risk scores

\begin{tabular}{|c|c|c|c|c|c|}
\hline & $D: A: D^{*}(n=362) n(\%)$ & FRSt $(n=382) n(\%)$ & ASCVD $\neq$ (\%) & QRISK2§ (n=376) n (\%) & RAMA-EGAT $(n=376) n(\%)$ \\
\hline \multicolumn{6}{|l|}{ Risk profile } \\
\hline High & $9(2.5)$ & & $33(16.3)$ & & \\
\hline Intermediate & $123(33.9)$ & & $19(9.4)$ & & \\
\hline Low & $230(63.5)$ & & $150(74.3)$ & & \\
\hline Kappa statistic & 1 & - & 0.25 & - & - \\
\hline \multicolumn{6}{|l|}{ Risk per cent } \\
\hline$>20$ & & $12(3.1)$ & $3(1.5)$ & $13(3.5)$ & $2(0.5)$ \\
\hline $10-20$ & & $28(7.3)$ & $18(8.9)$ & $30(7.9)$ & $62(16.5)$ \\
\hline$<10$ & & $342(89.5)$ & $181(89.6)$ & $333(88.6)$ & $312(82.9)$ \\
\hline Kappa statistic & - & 1 & 0.48 & 0.67 & 0.57 \\
\hline $\begin{array}{l}\text { Percent difference in } 10 \text {-year } \\
\text { cumulative risk scores } 9\end{array}$ & & 12.8 & - & 36.5 & \\
\hline \multicolumn{6}{|l|}{ Lifetime risk } \\
\hline$<50 \%$ & - & $355(92.9)$ & $292(80.9)$ & $252(67)$ & - \\
\hline$\geq 50 \%$ & & $27(7.1)$ & $69(19.1)$ & $124(32.9)$ & \\
\hline \multicolumn{6}{|l|}{ Statin recommended } \\
\hline Yes & - & - & $64(32.0)$ & $43(11.4)$ & - \\
\hline No & & & $138(68.0)$ & 333 (88.6) & \\
\hline
\end{tabular}

All scores except the D:A:D score estimate a 10-year CVD risk.

${ }^{*} D: A: D$ score estimates a 5 -year CVD risk. High risk (>5\%), intermediate risk $(1 \%-5 \%)$, low risk $(<1 \%)$.

TFRS: Lifetime risk was derived using the Framingham 30-year CVD risk with lipids. Ten-year risk was derived using the score with lipids.

ҒASCVD: 10-year risk estimation and statin recommendations for 40-79years $(n=202)$. Lifetime risk estimated for 20-59years $(n=361)$. High risk $(\geq 7.5 \%)$, intermediate risk $(5 \%-7.5 \%)$, low risk $(<5 \%)$.

§QRISK2: Lifetime risk estimation was done using the QRISK lifetime CVD risk calculator, statin recommendations were based on NICE guidelines.

१Per cent difference was calculated as: ((cumulative CVD risk of study population - cumulative CVD risk of normal population)/ cumulative CVD risk of normal population)* 100 . The risks for the normal populations were abstracted from the risk calculators of the respective scores from their official websites.

ASCVD, Atherosclerotic Cardiovascular; CVD, cardiovascular disease; D:A:D, Data Collection on Adverse Effects of Anti-HIV Drugs Study; FRS: Framingham risk score; NICE, National Institute for Health and Care Excellence; RAMA-EGAT, Ramathibodi-Electricity Generating Authority of Thailand score.

was set to $1 \mathrm{mmol} / \mathrm{L}$ in those with low HDL; (5) 1.90 when a target systolic BP of $130 \mathrm{~mm} \mathrm{Hg}$ was set for those with high $\mathrm{BP}$; (6) 1.90 when CD4 counts were raised to 500 cells/ $\mu \mathrm{L}$ for

Table 4 Effect of different simulated scenarios on the D:A:D score corresponding to a $50 \%$ cumulative CVD risk

\section{D:A:D score}

corresponding to $50 \% \quad$ Per cent reduction cumulative CVD risk $\left(D_{50}\right)(\%)$

om actual data $D_{50}$ scores (\%)

\begin{tabular}{|c|c|c|}
\hline Actual data & 2.19 & - \\
\hline $\begin{array}{l}\text { Low HDL raised to } \\
1 \mathrm{mmol} / \mathrm{L}\end{array}$ & 2.05 & 6 \\
\hline $\begin{array}{l}\text { High total cholesterol } \\
\text { reduced to } 5.2 \mathrm{mmol} / \mathrm{L}\end{array}$ & 2.03 & 7 \\
\hline $\begin{array}{l}\text { Low CD4 counts raised to } \\
500 \text { cells/ } \mu \mathrm{L}\end{array}$ & 1.90 & 13 \\
\hline $\begin{array}{l}\text { High systolic blood } \\
\text { pressure lowered to } \\
130 \mathrm{~mm} \mathrm{Hg}\end{array}$ & 1.90 & 13 \\
\hline Smoking prevention & 1.90 & 13 \\
\hline Diabetes prevention & 1.84 & 16 \\
\hline Optimal (combination of & 1.23 & 44 \\
\hline
\end{tabular}

all scenarios above)

$D$ represents the median CVD D:A:D risk score following a per cent cumulative frequency calculation. The higher the score the more the risk of a CVD event over the next 5 years.

Percent reduction is obtained by the following method (Actual $D_{50}$ data score- $D_{50}$ score derived from a hypothetical scenario)/Actual data $D$ score*100.

CVD, cardiovascular disease; D:A:D, Data Collection on Adverse Effects of Anti-HIV Drugs Study; HDL, high-density lipoprotein. those with low counts and (7) 1.23 when all the first six conditions were met (figure 1).

\section{DISCUSSION}

Estimates from the D:A:D risk score indicate that a high proportion $(36 \%)$ of our study population is at intermediate or high risk for a CVD event in the next 5 years. While a recent study of an Asian cohort classified a much greater percentage of people as high risk, ${ }^{22}$ our results are consistent with findings from South Africa. ${ }^{23}$ However, a noteworthy difference between our study population and these two studies is the younger age of our study participants. This is consistent with what we already know about CVD among Asian Indians and underscores the importance of

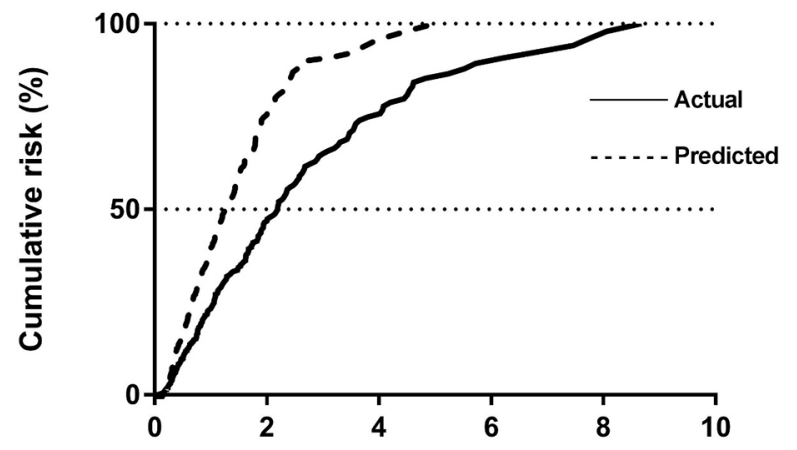

D:A:D score for CVD risk (\%)

Figure 1 Comparison between the cumulative CVD risk of the actual data and an optimal (predicted) scenario. CVD, cardiovascular disease. 
recognising the possibility that Asian Indian PLWH may have higher CVD risk at a younger age as compared with other HIV-infected populations. Thirty-two per cent of our study participants qualify for statin therapy under current ACC/AHA guidelines but only $2 \%$ were currently on statins. Juxtaposing our findings with those of a similar study from Tanzania ${ }^{24}$ shows an almost twofold higher statin requirement for our Indian HIV-infected population. While the proportion of participants that qualify for statins prescription decreases to $11 \%$ when using the NICE guidelines, our findings still highlight the deficit in therapeutic preventive services and a need to integrate them with the national HIV response.

In contrast to other studies where smoking cessation seemed to have the greatest impact in reducing CVD risk in HIV-infected adults, ${ }^{22} 25$ our findings suggest that for an Asian Indian population, diabetes prevention would provide the greatest benefit. This holds true even when stratification of D:A:D scores by gender is performed (see online supplementary table 1). The median cumulative CVD risk reduced by $16 \%$ when people with diabetes were assumed to be without, making the absence of diabetes the singular most prominent factor associated with decrease in CVD risk. Although the prevalence of diabetes in our study cohort was comparable to regional prevalence, prediabetes prevalence was $50 \%$ higher than the regional average (19\% vs $13 \%){ }^{26}$ Interestingly, we found that only $28 \%$ of the participants reported to have ever been screened for diabetes. Prioritising screening programmes is therefore crucial to reduce the burden of CVD in Asian Indian PLWH especially given the predisposition of Asian Indians for insulin resistance, ${ }^{15}$ high-incipient risk of diabetes denoted by high prevalence of metabolic syndrome in this group (21\%) and the possible induction of insulin resistance by HIV infection and treatment. ${ }^{27}$

Hypertension was another factor recognised in our analyses as a significant contributor to CVD risk. The prevalence of hypertension in our study population (22\%) was lower than the regional prevalence rates for either urban or rural Maharashtra (28\% and $24 \%) .{ }^{28}$ Nevertheless, what is concerning is that similar to diabetes, there appear to be gaps in the continuum between screening and treatment adherence. Among our cohort, 55\% had ever been screened for hypertension, of which $17 \%$ were diagnosed to be hypertensive, with only $57 \%$ taking medications that they had been prescribed (results not shown). Addressing this issue will require a concerted effort on the part of both clinicians and patients involving sensitisation and behavioural modification. Findings from preliminary studies implicate that the use of mineralocorticoid blockers in PLWH reduce metabolic complications. ${ }^{29}$ Thus, it is possible that in future, antihypertensive drugs become an integral part of managing PLWH in India, whereby they would have a direct CVD risk lowering effect by reducing blood pressure and an indirect effect by reducing insulin resistance.

Under an optimal situation, the six previously described hypothetical conditions; namely smokers become non-smokers, those with diabetes became without diabetes, all participants have recommended systolic blood pressure, cholesterol, HDL and CD4 count values, would be met. In such a setting, we observe that there is a $44 \%$ reduction in the median cumulative CVD risk score from what it presently is. In a resource-limited country like India, where public healthcare spending is low and behavioural interventions are challenging, the implementation of such strategies would require collaborative efforts from governmental agencies, clinicians and the general population. In this regard, NACO's new guidelines, increasing the threshold for starting
ART from 350 cells $/ \mu \mathrm{L}$ to 500 cells $/ \mu \mathrm{L},{ }^{30}$ is a welcome move and will probably go a long way in reducing the CVD risk in this vulnerable population.

One of the main limitations of our study is that we have no observable cardiovascular end points as yet to validate the risk predicted by different scoring systems. As we follow participants prospectively, we will have a better understanding whether the D:A:D score predicts a true risk of CVD or if there is a need to develop an ethnicity specific scoring system tailored for Asian Indians. Smoking was self-reported in our study, the true prevalence of which may have been affected by social desirability. We were also unable to draw comparisons regarding CVD risk with an HIV-uninfected group, as our sampling methodology did not include them. However as much is already known about CVD risk profiles in the general Asian Indian population, we assumed that the CVD-associated risk characteristics among HIV-uninfected individuals in Pune would not differ vastly from what has been published. ${ }^{12} 2628$ As mentioned earlier, other limitations include a small sample size and non-random sampling method, making our results less generalisable.

Nonetheless, our findings highlight a number of issues for HIV-infected Asian Indians that to our knowledge have not been discussed before. First, a large proportion of PLWH in India have an intermediate or high risk of CVD in the next 5 years, with only a small proportion currently on statins. Second, although diabetes and hypertension prevalence are similar or lower than the general population, the absence of robust screening programmes in the presence of HIV infection may confer PLWH in India with a higher CVD risk, and lastly implementation of simple strategies like achieving recommended blood pressure and cholesterol control would translate into significant reduction in CVD risk.

As HIV-infected individuals in India grow older and continue to live longer, the risk of CVD in these individuals is also likely to increase. An underlying genetic constitution coupled with dietary and behavioural practices that predispose to CVD, in the

\section{Key messages}

What is already known about this subject?

People living with HIV have a higher risk of cardiovascular disease. Inflammation, HIV drugs, virus-related and behavioural factors contribute to this risk. Asian Indians have cardiovascular diseases at younger ages compared with those who are of European descent. The resultant effect of the conflation of HIV infection and an Asian Indian ancestry among people living with HIV/AIDS in the region is not known.

\section{What does this study add?}

The distribution of cardiovascular disease risk factors or CVD risk scores for HIV-infected Asian Indians has never been reported. This study attempts to look at some of the traditional risk factors for cardiovascular disease as well as the risk profiles using standardised risk scores, for Asian Indians.

How might this impact on clinical practice? Findings from this study particularly the huge deficit found between statin requirement $(32 \%)$ and prescription (2\%) would alert HIV-medicine practitioners in India about the requirement to address the situation. We also found that a more stringent screening programme for diabetes among the HIV infected in India could potentially reduce the burden posed by cardiovascular diseases. 
setting of chronic inflammation, possibly increases the risk of CVD more than other HIV-infected populations. It is critical to assess and classify the burden that CVD will pose in PLHIV in India over the coming years and plan now for interventions to reduce CVD risk.

Correction notice This paper has been amended since it was published Online First. Owing to a scripting error, some of the publisher names in the references were replaced with 'BMJ Publishing Group'. This only affected the full text version, not the PDF. We have since corrected these errors and the correct publishers have been inserted into the references.

Acknowledgements We would like to thank Manjushree Bendre and Suhasini Surwase, study counsellors involved in data collection. We also extend our gratitude to Rupali Ahire and Shweta Potdar who were the laboratory technicians for this study. Our sincerest gratitude goes out to all participants in this study, who gave us their time to be part of all study procedures.

Contributors $D K, N G, A D, A G, V M$ conceived the study idea. NG, VM, SP, AD framed the study design. IPM, SP, AD implemented study procedures. IPM conceived the idea for this particular manuscript; analysed and interpreted data and drafted the preliminary manuscript. RS, SS, SP provided clinical input to contextualise the study findings. DS, VK, PD helped in the acquisition and interpretation of laboratory data. All authors have critically evaluated the manuscript and provided intellectual inputs. All authors approve of the final revised version submitted for publication.

Funding Thiswork was supported by the American Foundation for AIDS Research from the USNational Institutes of Health, National Institute of Allergy and InfectiousDiseases, Eunice Kennedy Shriver National Institute of Child Health and HumanDevelopment, and National Cancer Institute as part of the International Epidemiologic Databases to Evaluate AIDS [U01AI069907] and the Nationallnstitutes of Health funded Johns Hopkins Baltimore-Washington-India ClinicalTrials Unit for NIAID Networks [UM1AI069465]. The content of this paper issolely the responsibility of the authors and does not necessary represent theofficial views of the funders.

Competing interests None declared.

Patient consent Obtained.

Ethics approval BGJMC Ethics Committee and Johns Hopkins University Institutional Review Board.

Provenance and peer review Not commissioned; externally peer reviewed.

Data sharing statement The authors will make data available to the scientific community with as few restrictions as feasible, while retaining exclusive use until the primary research questions for which the study was devised have been answered and major outputs have been published. Following this, all available data can be obtained by contacting the corresponding author.

(c) Article author(s) (or their employer(s) unless otherwise stated in the text of the article) 2017. All rights reserved. No commercial use is permitted unless otherwise expressly granted.

\section{REFERENCES}

1 National AIDS Control Organisation \& National Institute of Medical Statistics, ICMR Ministry of Health \& Family Welfare Government of India. India HIV estimations technical report, 2015.

2 Care Support and Treatment Division, National AIDS Control Organisation, Department of AIDS Control Ministry of Health and Family Welfare Government of India. Journey of ART programme in India story of a decade, celebrating 10 years of success April 2004 - March 2014, 2014

3 Miller CJ, Baker JV, Bormann AM, et al. Adjudicated morbidity and mortality outcomes by age among individuals with HIV infection on suppressive antiretroviral therapy. PLoS One 2014;9:e95061.

4 Mocroft A, Brettle R, Kirk O, et al. Changes in the cause of death among HIV positive subjects across Europe: results from the EuroSIDA study. AIDS 2002;16:1663-71.
5 Freiberg MS, Chang CC, Kuller LH, et al. HIV infection and the risk of acute myocardial infarction. JAMA Intern Med 2013;173:614-22.

6 Paisible AL, Chang CC, So-Armah KA, et al. HIV infection, cardiovascular disease risk factor profile, and risk for acute myocardial infarction. J Acquir Immune Defic Syndr 2015;68:209-16.

7 Post WS, Budoff M, Kingsley L, et al. Associations between HIV infection and subclinical coronary atherosclerosis. Ann Intern Med 2014;160:458-67.

8 Bahrami H, Budoff M, Haberlen SA, et al. Inflammatory markers associated with subclinical coronary artery disease: the Multicenter AIDS Cohort Study. J Am Heart Assoc 2016;5:e003371.

9 Triant VA, Lee H, Hadigan C, et al. Increased acute myocardial infarction rates and cardiovascular risk factors among patients with human immunodeficiency virus disease. J Clin Endocrinol Metab 2007;92:2506-12.

10 Lall P, Saifi R, Kamarulzaman A. Tobacco consumption among HIV-Positive respondents: findings from the Third Round of the National Family Health Survey. Nicotine Tob Res 2016;18:2185-93.

11 Institute of Health Metrics and Evaluation. GBD compare. 2013 http://vizhub. healthdata.org/gbd-compare/ (accessed 28 July 2016).

12 Harikrishnan A, Leeder S, Huffman M, et al. A race against time: The challenge of cardiovascular disease in developing economies. 2nd edn. New delhi, India: New Delhi centre for chronic disease control, 2014.

13 Gupta R, Misra A, Vikram NK, et al. Younger age of escalation of cardiovascular risk factors in Asian Indian subjects. BMC Cardiovasc Disord 2009;9:28.

14 Joshi P, Islam S, Pais P, et al. Risk factors for early myocardial infarction in South Asians compared with individuals in other countries. JAMA 2007;297:286-94.

15 O'Keefe EL, DiNicolantonio JJ, Patil H, et al. Lifestyle choices fuel epidemics of Diabetes and Cardiovascular Disease among Asian Indians. Prog Cardiovasc Dis 2016;58:505-13.

16 Lundgren JD, Babiker AG, Gordin F, et al. Initiation of antiretroviral therapy in early asymptomatic HIV infection. N Engl J Med 2015;373:795-807.

17 QRISK lifetime. https://qrisk.org/lifetime/ (accessed 30 Jul 2016).

18 QRISK2-2016. https://qrisk.org/2016/ (accessed 15 Jul 2016).

19 Framingham Heart Study Cardiovascular disease (10 -year risk). http://www. framinghamheartstudy.org/risk-functions/cardiovascular-disease/10-year-risk.php (accessed 20 Jul 2016)

20 Goff DC, Lloyd-Jones DM, Bennett G, et al. 2013 ACC/AHA guideline on the assessment of cardiovascular risk: a report of the American College of Cardiology/ American Heart Association Task Force on Practice guidelines. J Am Coll Cardiol 2014:63(25 Pt B):2935-59.

21 NICE. Cardiovascular disease: risk assessment and reduction, including lipid modification. 2014 https:/www.nice.org.uk/guidance/cg181/chapter/1Recommendations (accessed 25 Jul 2016).

22 Do TC, Boettiger D, Law M, et al. Smoking and projected cardiovascular risk in an HIV-positive asian regional cohort. HIV Med 2016;17:542-9.

23 Mashinya F, Alberts M, Van Geertruyden JP, et al. Assessment of cardiovascular risk factors in people with HIV infection treated with ART in rural South Africa: a cross sectional study. AIDS Res Ther 2015;12:42-015-0083-6.

24 Kingery JR, Alfred Y, Smart LR, et al. Short-term and long-term cardiovascular risk, metabolic syndrome and HIV in Tanzania. Heart 2016;102:1200-5.

25 Petoumenos K, Worm S, Reiss P, et al. Rates of cardiovascular disease following smoking cessation in patients with HIV infection: results from the D:a:D study $\left({ }^{*}\right)$. HIV Med 2011:12:412-21.

26 Anjana RM, Pradeepa R, Deepa M, et al. Prevalence of diabetes and prediabetes (impaired fasting glucose and/or impaired glucose tolerance) in urban and rural India: phase I results of the Indian Council of Medical Research-INdia DIABetes (ICMRINDIAB) study. Diabetologia 2011;54:3022-7.

27 Hruz PW. Molecular mechanisms for insulin resistance in treated HIV-infection. Best Pract Res Clin Endocrinol Metab 2011;25:459-68.

28 Bhansali A, Dhandania VK, Deepa M, et al. Prevalence of and risk factors for hypertension in urban and rural India: the ICMR-INDIAB study. J Hum Hypertens 2015:29:204-9.

29 Srinivasa S, Fitch KV, Wong K, et al. RAAS activation is Associated with visceral adiposity and insulin resistance among HIV-infected patients. J Clin Endocrinol Metab 2015:100:2873-82.

30 Times of India. $2015 \mathrm{Http} / / / \mathrm{www}$.pressreader.com/india/the-times-of-india-mumbaiedition/20151130/281672548862767 (accessed 17 Jul 2016). 